\title{
PULSED POWER SUPPLY FOR THREE APS SEPTUM MAGNETS
}

ABSTRACT

Three septum magnets will be operated at a repetition-rate of $2 \mathrm{~Hz}$. Two of the septum magnets are identical and operate at the same values; these are the synchrotron extraction and the storage ring injection magnets. They are transformer septum magnets, with a primary inductance of $23 \mu \mathrm{H}$ and resistance of $6.3 \mathrm{~m} \Omega$, and must be pulsed at a $2 \mathrm{~Hz}$ rate to extract beam from the synchrotron and inject beam into the storage ring at $7.7 \mathrm{GeV}$. The third septum magnet is used to inject electrons into the synchrotron at $650 \mathrm{MeV}$ or positrons at $450 \mathrm{MeV}$. It is also a transformer septum magnet, with a primary inductance of $21 \mu \mathrm{H}$ and resistance of $6.7 \mathrm{~m} \Omega$, and must be pulsed at a $2 \mathrm{~Hz}$ rate. A design study was performed of the power supply proposed in the APS Title I design. This supply produces a pulse that is approximately a half-sine-wave with a base width of approximately $1 / 3 \mathrm{~ms}$; its peakcurrent is adjustable from $470 \mathrm{~A}$ to $4.7 \mathrm{kA}$ and is repeatable within $\pm 0.05 \%$. The septum steel is reset by a half-sine pulse of reverse polarity a few milliseconds after the forward current pulse. No beam is present during reset. The use of the transformer design minimizes the cost of the capacitors used for energy storage.

\section{INTRODUCTION}

The septum magnets could be operated dc from a beam perspective. If they were operating $d c$ the current leads would be required to be 47 to 63 times as large and the power loss in the magnet would be 2209 to 3969 times the pulsed operation, this would increase the power density in the septum edge to a level that would result in unacceptable operating temperature.

During the injection of the $650 \mathrm{MeV}$ electron or $450 \mathrm{MeV}$ positron beam from the Linac or PAR into the Synchrotron the septum magnet will be pulsed. Also, during extraction of the 7.7 $\mathrm{GeV}$ electron or positron beam from the Synchrotron and the injection into the Storage Ring, 3 septum magnets will be used for 


\section{DISCLAIMER}

Portions of this document may be illegible in electronic image products. Images are produced from the best available original document. 
each function, 2 are dc and 1 is pulsed. All 3 pulsed septum magnets have approximately the same rise and fall time. The septum's current pulse is required to be $<1 \mathrm{~ms}$ and the flattop time $>1 \mu \mathrm{s}$. These requirements are met with a capacitor discharge circuit that is resonant with the septum magnet at a frequency of approximately $1500 \mathrm{~Hz}$. The peak current for the Synchrotron injection septum is $4227 \mathrm{~A}$ in the transformer primary and $16888 \mathrm{~A}$ in the secondary. The other 2 pulsed septums are identical and operate at approximately the same required current of $3800 \mathrm{~A}$ in the transformer primary and $11400 \mathrm{~A}$ in the secondary. These requirements can also be met with a half sinewave pulse. This is accomplished by discharging the energy stored in capacitor bank $\left(\mathrm{C}_{2}\right)$ into the magnet as illustrated by Fig. 1. On triggering the forward thyristor $S_{3}$ the energy stored in $C_{2}$ between pulses is discharged into the magnet circuit. $S_{3}$ turns off at the end of the first half cycle of the damped oscillation. $C_{2}$ is then left with a smaller charge of opposite polarity until the reverse thyristor $S_{4}$ is triggered and the second half cycle takes place with current flowing in the opposite direction. The difference between the original and the final charge is furnished by the charging supply between septum pulses.

\section{Switching Circuits}

\section{Circuit Equations}

The switching circuits of these 3 septums operate in the same way as the injection/extraction septum for PAR.[1] When the capacitor, $\mathrm{C}_{2}$, of Fig. 1 is discharged into the load, an oscillatory current will result provided that the total resistance in the circuit is sufficiently low.

The resonant frequency of the circuit is:

$$
\mathrm{fr}=\mathrm{B} / 2 \pi \quad\left[\mathrm{s}^{-1}\right]
$$

$$
\begin{aligned}
& \text { where } B=\left(\left(1 / L m C_{2}\right)-\left(R_{m}{ }^{2} / 4 L_{m}{ }^{2}\right)\right)^{0.5} \quad\left[s^{-1}\right] \\
& \mathrm{C}_{2}=\text { capacitor bank } \\
& \mathrm{Lm}=\text { total circuit inductance } \quad[\mathrm{H}] \\
& \mathrm{R}_{\mathrm{m}}=\text { total circuit resistance } \quad[\Omega]
\end{aligned}
$$

The current at any time is: 


$$
i=\left(E / B L_{m}\right) e^{-\alpha t} \sin B t
$$

where $\mathrm{t}=$ time after discharge starts

$$
\alpha=R_{m} / 2 \mathrm{Lm}
$$

The required voltage on $\mathrm{C}_{2}$ for the different peak operating currents is:

$$
E_{C 2}=i \beta L_{m / e^{-\alpha t}} \sin B t \quad[V]
$$

These values are shown in Table 1 for each of the 3 magnets operating at 2 different energies.

The time at which the current reaches its first peak is:

$$
\text { tp }=1 / \beta \tan ^{-1} B / \alpha
$$

The first current peak does not occur at precisely the first quarter period of the discharge cycle, but at a previous point in time. This is shown by the circuit simulation graphed in Fig. 2. The term tan ${ }^{1} B / \alpha$ describes the phase angle at which the peak current occurs.

In this application, $R_{m}$ is made appreciably less than the value for critical damping. With $1 / L_{m} C_{2}>R_{m}{ }^{2} / 4 \mathrm{Lm}^{2}$ we can write $B \approx 1 /\left(L_{m} C_{2}\right)^{0.5}$ and the above equations can be simplified to:

$$
\begin{aligned}
& \mathrm{fr} \approx 1 /\left(2 \pi\left(\mathrm{Lm}_{\mathrm{m}} \mathrm{C}_{2}\right)^{0.5}\right) \\
& \mathrm{i} \approx \mathrm{E}_{\mathrm{C} 2}\left(\mathrm{C}_{2} / \mathrm{Lm}_{\mathrm{m}}\right)^{0.5} \mathrm{e}^{-\alpha \mathrm{t}} \sin \mathrm{t}\left(\mathrm{L}_{\mathrm{m}} \mathrm{C}_{2}\right)^{0.5}[\mathrm{~A}]
\end{aligned}
$$

The peak current is then

$$
I_{p} \approx E_{C 2}\left(C_{2} / L_{m}\right)^{0.5} e^{-\left(\left(\pi R_{m} / 4\right)\left(C_{2} / L_{m}\right)^{0.5}\right)}[A]
$$

and the voltage on the first reversal becomes

$$
E_{C 2} \approx-E_{C 2} e^{-\left(\left(\pi R_{m} / 2\right)\left(C_{2} / L m\right)^{0.5}\right)} \quad[V]
$$


Critical damping occurs at a resistance:

$$
R_{m}=2\left(L_{m} / C_{2}\right)^{0.5}
$$

\section{Controlled Charging-Choke Circuit}

Fig. 3 shows the controlled charging-choke circuit and the capacitor discharge circuit of Fig. 1 combined. The discharge capacitor $C_{2}$ is charged and recharged to make up the circuit losses incurred in pulsing the magnet. These losses are made up from a commercial $1 \mathrm{~kW}$ regulated dc power supply, PS1, and a capacitor bank, $C_{f}$. PS1 has constant voltage and constant current mode of operation with automatic crossover. This allows the direct connection to $C_{f}$, as PS1 will operate in the constant current mode until crossover occurs at the output voltage set point. The key power supply specifications are given in Table 2. The capacitor bank $C_{f}$ is used to allow the losses to be made up at a fixed time before the next pulse of the main switching circuit. The controlled charging circuit consists of $L_{2}, C_{2}, S_{1}$ and $S_{2}$. Gating on of $S_{1}$ is used to start the charging of $\mathrm{C}_{2}$ from the dc power supply. At time $t_{0}$ the supply voltage $E$ begins to drive an essentially sinusoidal current through the charging circuit.

$$
E=i R_{2}+L_{2}(d i / d t)+\left(1 / C_{2}\right) \int_{0}^{t_{1}} i_{c 2} d t
$$

At time $t_{1}$ the current is at its peak and

$$
\begin{aligned}
& L_{2} d i / d t=0, \\
& E=i R_{2}+\left(1 / C_{2}\right) \int_{0}^{t 1} i_{c 2} d t .
\end{aligned}
$$

Between $t_{1}$ and $t_{2}$ the decaying charging current generates a voltage $\mathrm{L}_{2}$ (di/dt) which aids the supply voltage to charge the capacitor $C_{2}$ to a voltage larger than $E$. In the case where $R \Rightarrow 0$, this voltage will be, at time $t_{2}$,

$$
e_{C 2}=E+L(d i / d t)=2 E \text {. }
$$


By providing a thyristor across the charging choke as shown in Fig. 3 the charging cycle can be terminated at any instant between times $t_{1}$ and $t_{2}$. A fraction of the capacitor voltage $e_{c 2}$ is compared with a reference voltage. At time $t_{r}$ when the capacitor voltage is $\geq$ the supply voltage, a pulse can be generated which turns on $\mathrm{S}_{2}$. With $\mathrm{S}_{2}$ conducting, the driving voltage $L_{2}$ (di/dt) is removed from the circuit and the capacitor voltage $e_{c 2}$ is larger than the power supply voltage $E$, thyristor $S_{1}$ is back-biased and the charging current $i_{c 2}$ stops. The current $i_{L 2}$ flowing in choke $L_{2}$ at time $t_{r}$ will decay with a time constant $L_{2} / R_{2}$, where $R_{2}$ is the resistance of the choke and thyristor, $S_{2}$, circuit. Thyristor $S_{2}$ remains on until the time $S_{1}$ is gated on starting the charge cycle again, or the choke current decays to 0 . The current $i_{\mathrm{L} 2}$ flowing in the choke when $S_{2}$ is turned off will aid in charging capacitor $\mathrm{C}_{2}$ (the energy $0.5 \mathrm{~L}_{2} \mathrm{i}_{\mathrm{L} 2}{ }^{2}$ is returned to the circuit). This makes the circuit very efficient.

\section{Warning}

It should be noted that the $Q$ of the discharge circuit in Fig. 1 should be $<5$ for this charging circuit to operate properly. As the $Q$ increases the current flowing in the choke $L_{2}$ will decrease. This in turn decreases the operating range of the charging circuit.

\section{Pulsing Directly Inte the Load}

Heat losses in the magnet can be cut by approximately $1 / 3$ and the circuit efficiency can be increased by not gating $S_{4}$, and resetting the required output voltage of PS1.

\section{Simulation Results}

Two septum circuits with 2 beam energies per circuit were simulated with the magnets each having a $Q$ of 2 . The charge voltages used are given in Table 1 . The peak and rms voltages/currents for all the pulsed septum magnets operating at 2 $\mathrm{Hz}$ and the waveforms for the synchrotron injection septum power supply at the different circuit nodes, are shown in Fig. 4 a, b and c. These simulations were done using a piecewise simulation program. [2]. The simulated waveforms have a varied time axis so that they 
show in detail what happens during the charge and discharge of $C_{2}$.

\section{Control and Interlock Logic}

Control logic is shown in Fig. 5. Control is accomplished with 3 gate pulses from the power supply control unit (PSCU) or a master clock and 3 interlock signals from the interlock circuit.

The "Start Charge" pulse is optically coupled to AND/1 with a signal from the interlock trip circuit. When the trip signal is low the power supply is completely shutoff and crowbarred. When both the "Start Charge" pulse and the interlock are logic 1s then the AND's output is true (1) setting the flip-flop, FF/1, causing single shot, (SS)/2's Q output to go high and stay there for $250 \mu \mathrm{s}$. This pulse is amplified and coupled with the pulse transformer to gate Thyristor S1. This starts the resonant charge of $\mathrm{C} 2$ from $\mathrm{Cf}$ through $\mathrm{L} 2$, as shown in Fig. 4.

At the time $S S / 2$ is triggered, $S S / 3$ is also triggered, which causes its $Q /$ not output to go low. The pulse width of $S S / 3$ is $5 \mathrm{~ms}$ and at the end of this pulse $Q /$ not goes high triggering $S S / 4$. The $Q$ output pulse of $\mathrm{SS} / 4$ is $9 \mathrm{~ms}$ and is used as a window during which time Ec2 is compared to the DAC voltage and Ec2 is also compared with Ecf in the interlock circuit. If Ec2 is greater than both voltages, Ecf, and the DAC then all 3 inputs to AND/2 are 1s. This causes the AND's output to be true (1) setting the flip-flop, FF/2, causing single shot, (SS)/5's $Q$ output to go high and stay there for $250 \mu \mathrm{s}$. This pulse is amplified and coupled with pulse transformer to gate Thyristor S2. This stops the resonant charge of $\mathrm{C} 2$ by crowbarring L2, as shown in Fig. 4.

At the end of the $S S / 5$ Q output pulse $S S / 7$ is triggered causing a $Q$ output pulse of $S S / 7$. The pulse is $15 \mathrm{~ms}$ and is used as a window during which time, as long as the trip circuit is satisfied, a "Magnet Current" pulse can wide. This causes the AND's output to be true (1) setting the flip-flop, FF/4, causing single shot, (SS)/8's $Q$ output to go high and stay there for $150 \mu \mathrm{s}$. This pulse is amplified and coupled with the pulse transformer to gate Thyristor S3. This starts the resonant current pulse of $\mathrm{Lm}$ by discharging $\mathrm{C}_{2}$ and recharging with the other polarity, as shown in Fig. 2.

At the end of the SS/8 Q output pulse $S S / 10$ is triggered causing a $Q$ output pulse. Also at the time the "Magnet Current" pulse $S S / 11$ is also triggered causing its $Q /$ not output to go low. The pulse width of $S S / 11$ is $0.5 \mathrm{~ms}$ and at the end of this pulse 
$Q /$ not goes high triggering $S S / 12$. The $Q$ output pulse of $S S / 12$ is $10 \mu s$ wide and is used to cause the AND's output to switch to true (1) setting the flip-flop, FF/5, causing single shot, (SS)/13's $Q$ output to go high and stay there for $150 \mu \mathrm{s}$. This pulse is amplified and coupled with pulse transformer to gate Thyristor S4. This starts the resonant current pulse of $\mathrm{Lm}$ by discharging $\mathrm{C} 2$ and recharging with the other polarity, as shown in Fig. 1. The current pulse resets the magnet core.

At the end of the $S S / 13 Q$ output pulse $S S / 16$ causes its $\mathrm{Q} /$ not output to go low. The pulse width of $S S / 16$ is $250 \mathrm{~ms}$ and at the end of this pulse $Q /$ not goes high triggering $S S / 15$. The $Q$ output pulse of SS/15 is $10 \mu$ s and is ORed with a "Magnet Reset" pulse. Either pulse will reset all flip/flops (FF) with a $10 \mu \mathrm{s}$ pulse from SS/14.

\title{
References
}

1. D. G. McGhee, "Pulsed Power Supply for PAR Injection/Extraction Septum Magnet", ANL Light-Source Note, LS159, September 23, 1990

2. D. E. Piccone, I. L. Somos, and W. H. Tobin, "Piecewise Simulation (PS) Computation Method for Computing Transient Phenomena", IEEE-IAS Annual Meeting, September 1975, Page 326-331.

\section{DISCLAIMER}

\begin{abstract}
This report was prepared as an account of work sponsored by an agency of the United States Government. Neither the United States Government nor any agency thereof, nor any of their employees, makes any warranty, express or implied, or assumes any legal liability or responsibility for the accuracy, completeness, or usefulness of any information, apparatus, product, or process disclosed, or represents that its use would not infringe privately owned rights. Reference herein to any specific commercial product, process, or service by trade name, trademark, manufacturer, or otherwise does not necessarily constitute or imply its endorsement, recommendation, or favoring by the United States Government or any agency thereof. The views and opinions of authors expressed herein do not necessarily state or reflect those of the United States Government or any agency thereof.
\end{abstract}




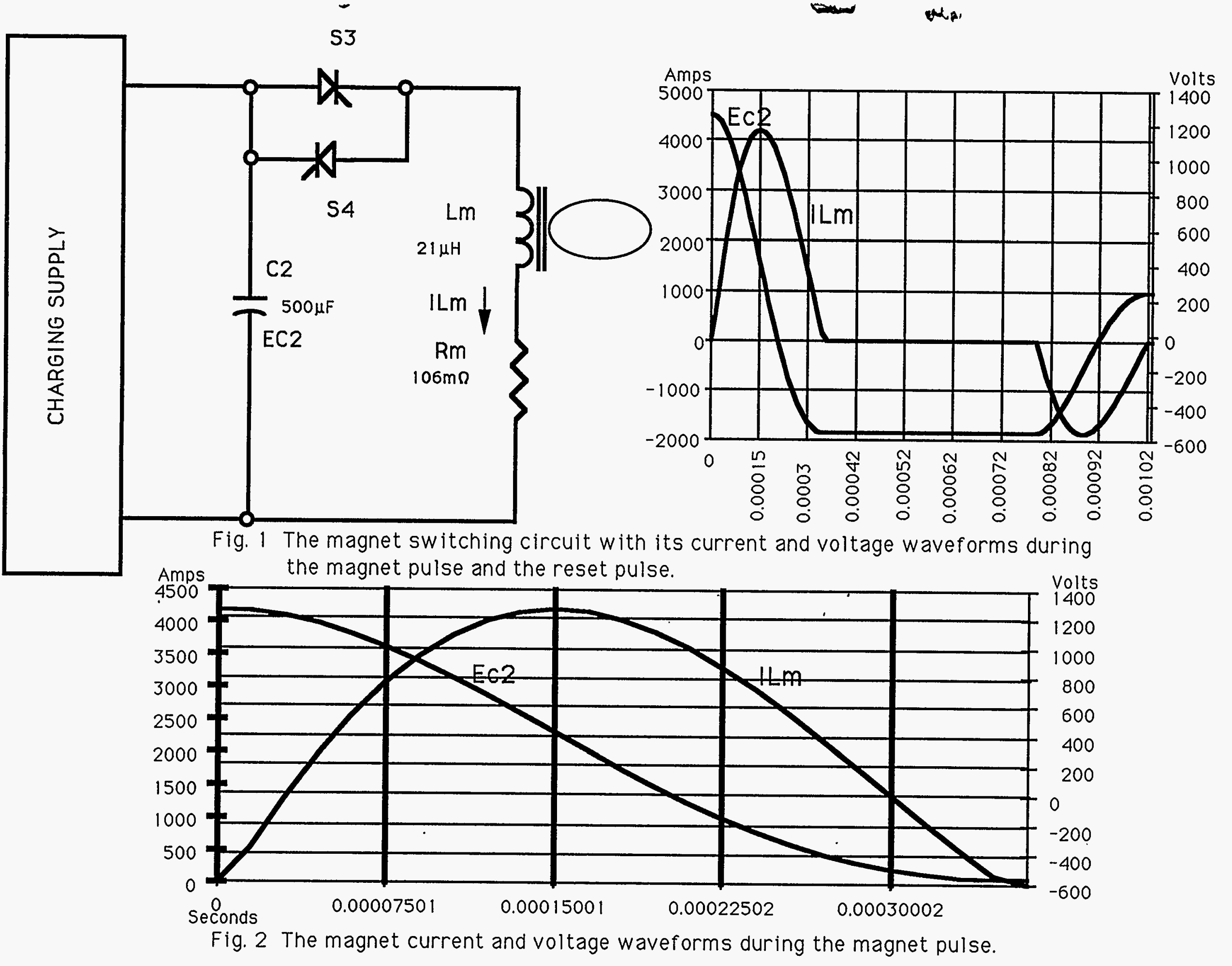




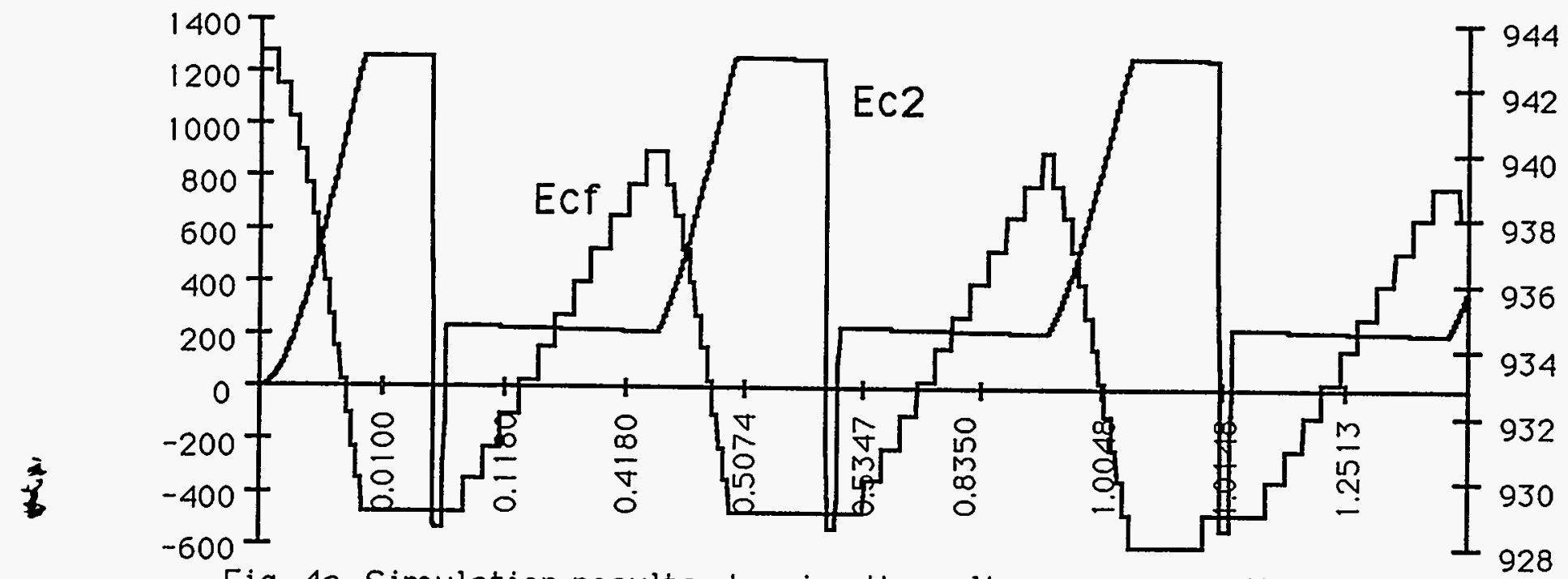

Fig. 4a Simulation results showing the voltages on capacitors $\mathrm{Cf}$ and $\mathrm{C} 2$

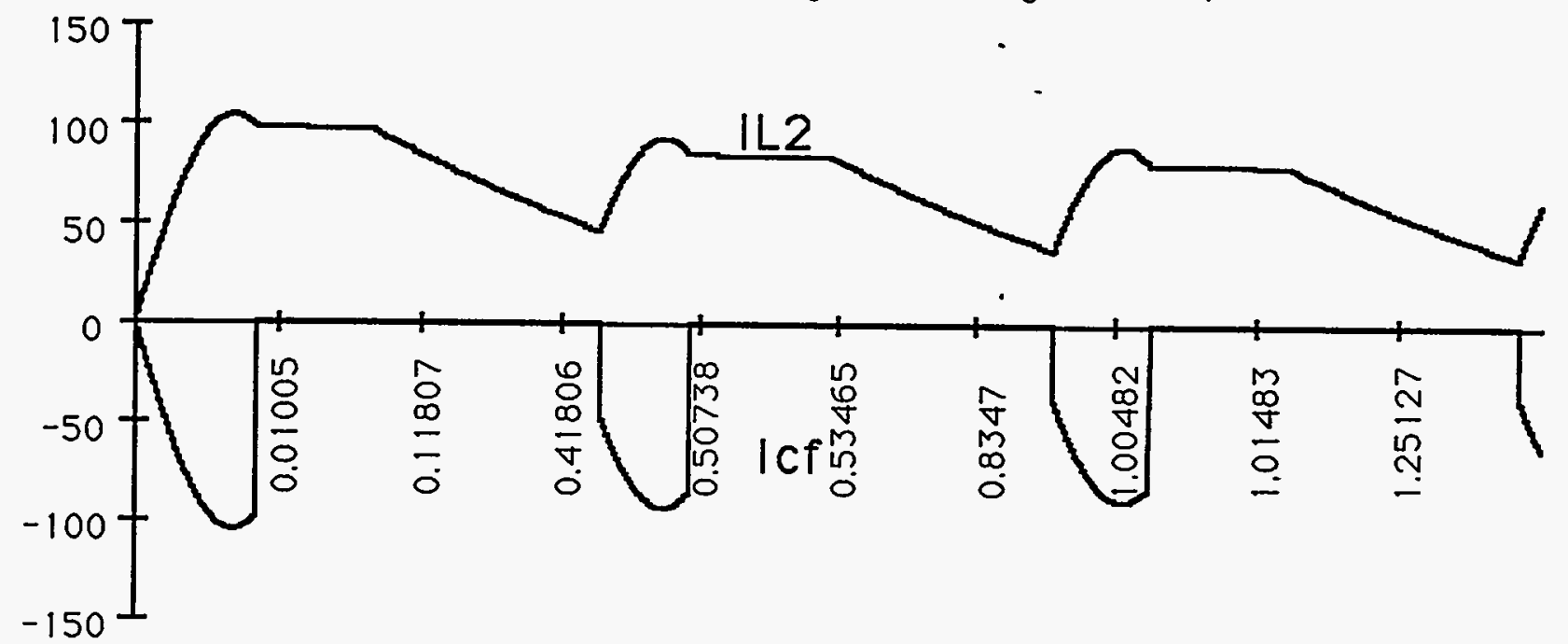

Fig. $4 \mathrm{~b}$ Simulation results showing the currents in capacitor $\mathrm{Cf}$ and inductor $\mathrm{L} 2$

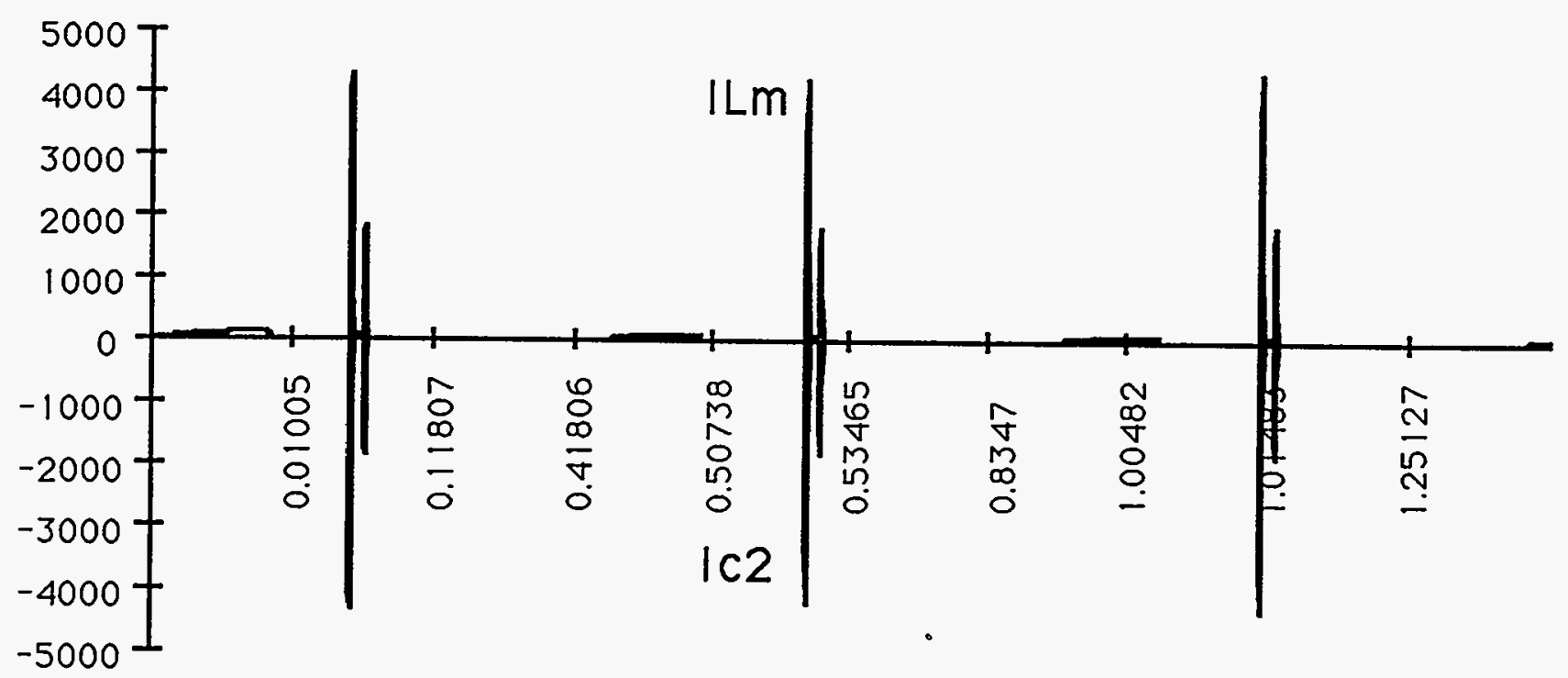

Fig. $4 \mathrm{C}$ Simulation results showing the currents in capacitor $\mathrm{C} 2$ and magnet $\mathrm{Lm}$. 


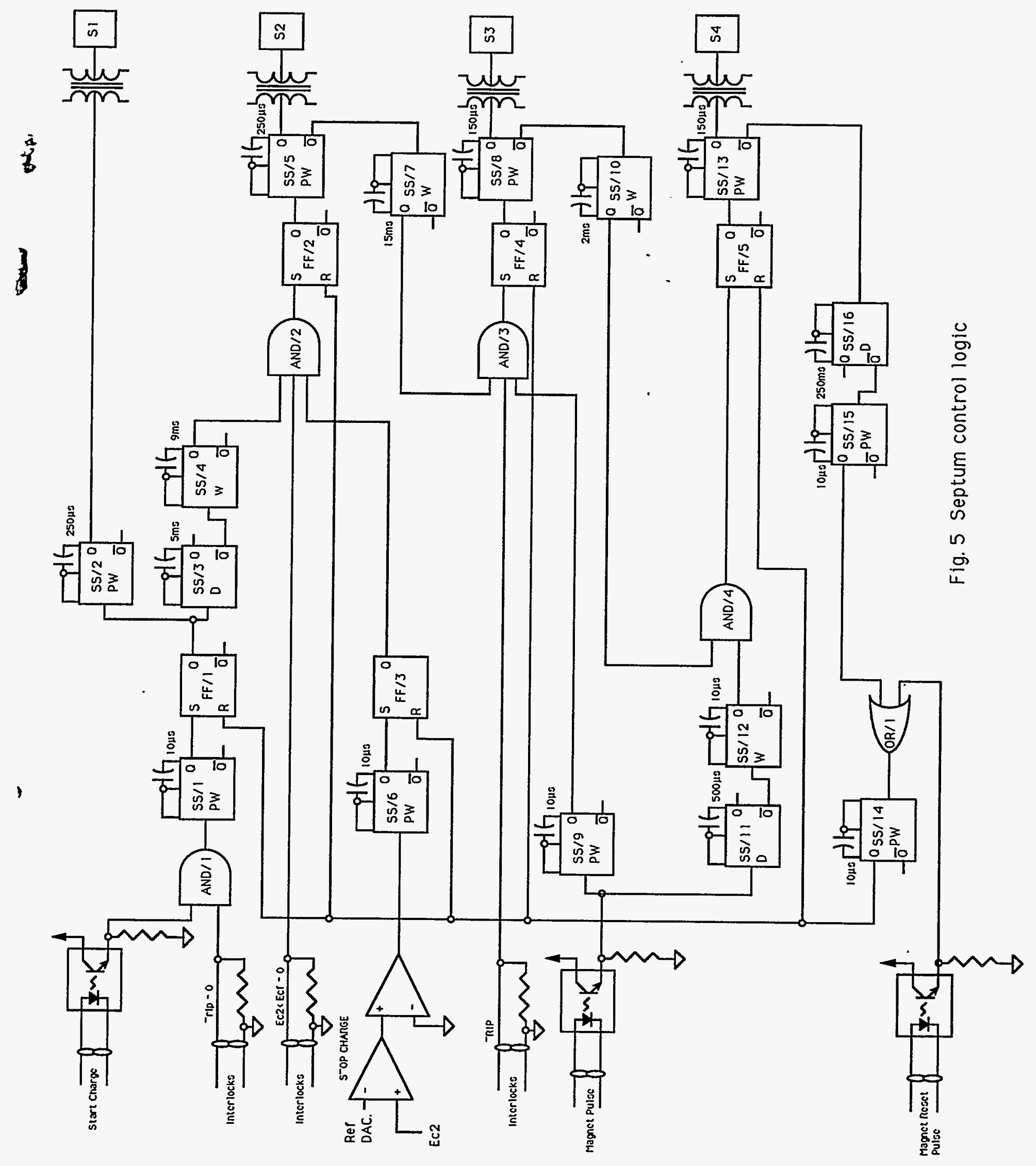


Table 1 APS's $2 \mathrm{~Hz}$ septum systems operating voltages and currents

\begin{tabular}{|c|c|c|c|c|c|c|}
\hline Machine & Synchrotron & Synchrotron & Synchrotron & Synchrotron & Storage Ring & Storage Ring \\
\hline Septum & Inlection & Injection & Extraction & Extraction & Injection & Injection \\
\hline Energy & $650 \mathrm{MeV}$ & $450 \mathrm{MOV}$ & $7.7 \mathrm{GoV}$ & $7 \mathrm{G} \theta \mathrm{V}$ & $7.7 \mathrm{GeV}$ & $7 \mathrm{GeV}$ \\
\hline Poak Primary Current & 4227 & 2926 & 3800 & 3455 & 3800 & 3455 \\
\hline Primary Magnet Inductance & 0.000021 & 0.000021 & 0.000023 & 0.000023 & 0.000023 & 0.000023 \\
\hline Capacitor Voltage C2 IEC2.C & 1258 & 871 & 1166 & 1060 & 1166 & 1060 \\
\hline PS1 Voltage & 944 & 653 & 874 & 795 & 874 & 795 \\
\hline \multicolumn{7}{|l|}{ Simuninor. } \\
\hline \multicolumn{7}{|l|}{ 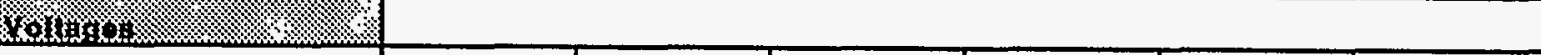 } \\
\hline Ecf--\{max\}peak & 943 & 653 & 874 & 795 & 874 & 795 \\
\hline Ecf--Imin\}peak & 928 & 643 & 861 & 783 & 861 & 783 \\
\hline Ecf--rms & 934 & 650 & 868 & 790 & 868 & 790 \\
\hline Ec2--_max\}peak & 1258 & 871 & 1166 & 1060 & 1166 & 1060 \\
\hline Ec2--Iminlpoak & -537 & -371 & .518 & -471 & -518 & -471 \\
\hline Ec2--rms & 288 & 198 & 280 & 254 & 280 & 254 \\
\hline \multicolumn{7}{|l|}{ 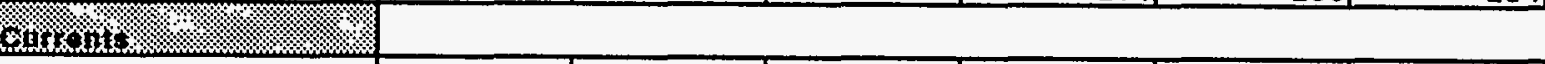 } \\
\hline Icf--(max)peak & 1 & 1 & 1 & 1 & 1 & 1 \\
\hline Icf-- $\mid$ min $\mid$ peak & -105 & .72 & -97 & -88 & -97 & -88 \\
\hline lct--rms & 10 & 7 & 9 & 8 & 9 & 8 \\
\hline lo2--\{max\}peak & 1849 & 1279 & 1732 & 1575 & 1732 & 1575 \\
\hline lc2--|min\}peak & -4322 & -2990 & -3888 & -3535 & -3888 & -3535 \\
\hline Ic2--rms & 91 & 63 & 84 & 77 & 84 & 77 \\
\hline$\left(1 \mathrm{Lm}-\{\max )_{\text {peak }}\right.$ & 4321 & 2989 & 3887 & 3534 & 3887 & 3534 \\
\hline ILm-_minlpeak & -1850 & -1280 & -1733 & .1576 & -1733 & -1576 \\
\hline $1 \mathrm{Lm}-\mathrm{rms}$ & 90 & 63 & 84 & 76 & 84 & 76 \\
\hline IL2--\{max\}peak & 105 & 72 & 97 & 88 & 97 & 88 \\
\hline IL2--|min|peak & 2 & 1 & 2 & 1 & 2 & 1 \\
\hline ILL--rms & 64 & 40 & 57 & 50 & 57 & 50 \\
\hline
\end{tabular}


Table 2 PS1 Specifications

Qutput

1. Power:

2. Voltage:

3. Current:

4. Voltage Regulation for $\pm 10 \%$ input line:

$1 \mathrm{~kW}$

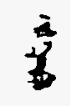

5. Current Regulation for $\pm 10 \%$ input line:

$0-1 k V$

$0-1 \mathrm{~A}$

$0.02 \%$

6. Ripple: $0.2 \%$

$0.1 \%$

7. Temperature Coefficient $\left(0\right.$ to $\left.50^{\circ} \mathrm{C}\right)$ : - $\begin{aligned} & \text { peak to peak } \\ & \pm 200 \mathrm{ppm} /{ }^{\circ} \mathrm{C}\end{aligned}$

8. Automatic Crossover from constant current to constant voltage

9. Efficiency:

$85 \%$ typical

Input

10. Power

$115 \mathrm{~V} \pm 10 \%$

@16A, 60Hz $230 \mathrm{~V} \pm 10 \%$

11. Control Interface @10A, 60Hz IEEE 488 